\title{
Carotid artery surgery: back to the future
}

\section{Cirurgia de artéria carótida: de volta para o futuro}

\author{
Marc Bosiers', Gustavo Henrique Dumont Kleinsorge², Koen Deloose', Túlio Pinho Navarro³
}

\begin{abstract}
In this study we performed 548 carotid revascularizations between 2006 and 2008 at the Department of Vascular Surgery of the A.Z. Sint-Blasius, Dendermonde, Belgium - a high-volume experienced center for carotid artery stenting (CAS). In 2006, our 30-day complication rates were 3.21 and $1.51 \%$ for symptomatic and asymptomatic patients, respectively. At that time, CAS represented approximately $86 \%$ of all cases we performed. However, the publication of the results of EVA-3S and SPACE studies drove us to reconsider our treatment allocation algorithm. In 2007 and 2008 , CAS procedures only accounted for $43 \%$ of all carotid procedures, which was a result of strict patient selection with comorbidities and high-risk lesions assessment, especially in symptomatic patients. Our current 30-day stroke/death rates are $1.24 \%$ for symptomatic patients and $0.53 \%$ for asymptomatic ones, which reflects that correct patient selection is the key to maintain CAS as a valuable alternative to carotid endarterectomy.
\end{abstract}

Keywords: Endarterectomy; endarterectomy, carotid; angioplasty; carotid stenosis; patient selection.

\section{Resumo}

Neste estudo, realizamos 548 revascularizações carotídeas entre 2006 e 2008 no Departamento de Cirurgia Vascular do A.Z. Sint-Blasius, Dendermonde, Bélgica - um centro de grande porte com experiência em angioplastia com stent de carótida (CAS, do inglês carotid artery stenting). Em 2006, nossas taxas de complicação em 30 dias foram de 3,21 e 1,51\% para pacientes sintomáticos e assintomáticos, respectivamente. Àquela época, a CAS representava aproximadamente $86 \%$ de todos os casos realizados; entretanto, a publicação dos resultados dos estudos EVA-3S e SPACE nos levaram a reconsiderar nosso algoritmo de tratamento. Em 2007 e 2008, os procedimentos de CAS representaram apenas $43 \%$ de todos os procedimentos carotídeos, o que foi resultado da seleção rigorosa de pacientes com avaliação de comorbidades e das lesões de alto risco, especialmente em pacientes sintomáticos. Nossas taxas atuais de AVE/óbito em 30 dias são de 1,24\% para pacientes sintomáticos e de 0,53\% para assintomáticos, refletindo que a seleção correta de pacientes é a chave para manter a CAS como uma alternativa válida à endarterectomia carotídea.

Palavras-chave: Endarterectomia; endarterectomia das carótidas; angioplastia; estenose das carótidas; seleção de pacientes.

\section{Introduction}

The first successful reconstruction of a stenotic internal carotid artery was performed in 1951 by Carrera et al. ${ }^{1}$ The first successful carotid reconstruction was performed by Carrera et al. in 1951 in a male patient suffering from stroke ${ }^{2}$. During this procedure, they cut out the stenosed area of the proximal internal carotid artery and made an end-to-end anastomosis using the transected proximal portion of the external carotid artery to the internal carotid artery. The operation was not reported until 1955. Many years later, DeBakey claimed he had performed a successful carotid endarterectomy (CEA) in $1953^{3}$. Over the years, it became the golden standard procedure for managing both symptomatic and asymptomatic carotid disease.

In the 1990s, carotid angioplasty and stenting became a valuable alternative to treat carotid artery disease. Technological developments led to superior endovascular devices, and, together with the increasing experience in this new treatment, significantly improved the results of carotid artery stenting $(\mathrm{CAS})^{4-7}$.

When CAS was introduced as a treatment option in our service in 1995,our experience in treating symptomatic and asymptomatic patients with surgery as well as with endovascular therapy accumulated.

The objective of this article was to illustrate how carotid artery disease is treated in our hospital and the changes we

Chief of the Department of Vascular Surgery of the AZ Sint-Blasius, Dendermonde, Belgium.

${ }^{2}$ Fellow of Vascular Surgery of the Department of Vascular Surgery of AZ Sint-Blasius, Dendermonde, Belgium.

${ }^{3}$ Coordinator of the Department of Vascular Surgery of the Hospital das Clínicas of Universidade Federal de Minas Gerais (UFMG), Belo Horizonte (MG), Brazil.

No conflicts of interest declared concerning the publication of this article.

Manuscript received: 07.08.09. Accepted for publication: 10.12.10

J Vasc Bras. 2011;10(1):44-49. 
have made over time to our selection algorithm for patients presenting with carotid artery disease.

\section{An overview of carotid artery revascularization in our service}

We made a retrospective analysis of 4,219 carotid artery revascularizations from 1987 to 2008.

Between 1987 and 1994, carotid endarterectomy was our preferred management in carotid artery disease (CAD), which was clinically indicated for treatment in patients with low risk for surgery. Following a review of our carotid interventions, we found a combined stroke and death rate of $2.30 \%$, and our results were comparable to other reported series, as can be seen in Figures 1 and 2.

At the beginning of 1995, CAS was introduced in our service. This procedure was performed only in high-risk patients (e.g. recent myocardial infarction, ejection fraction $<30 \%$ ).

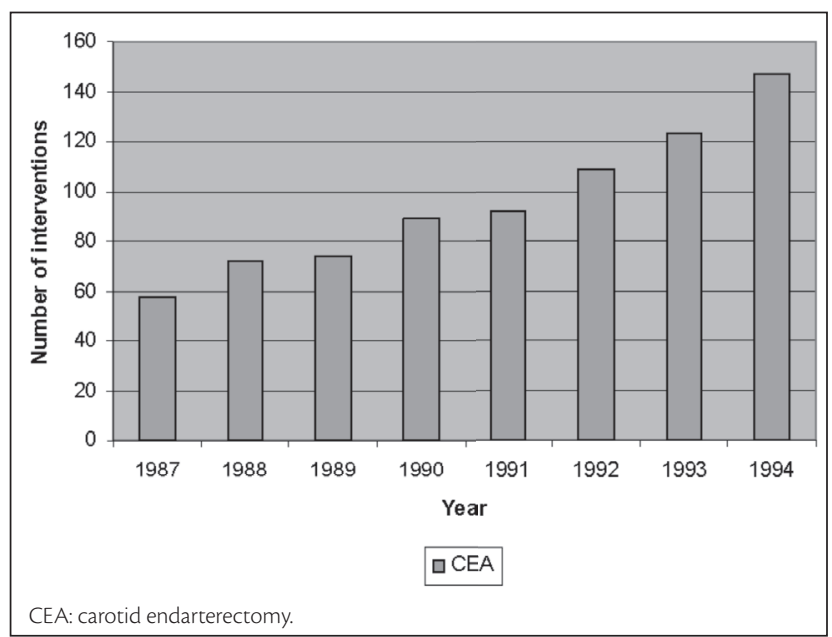

Figure 1 - Evolution of carotid interventions from 1987 to 1994

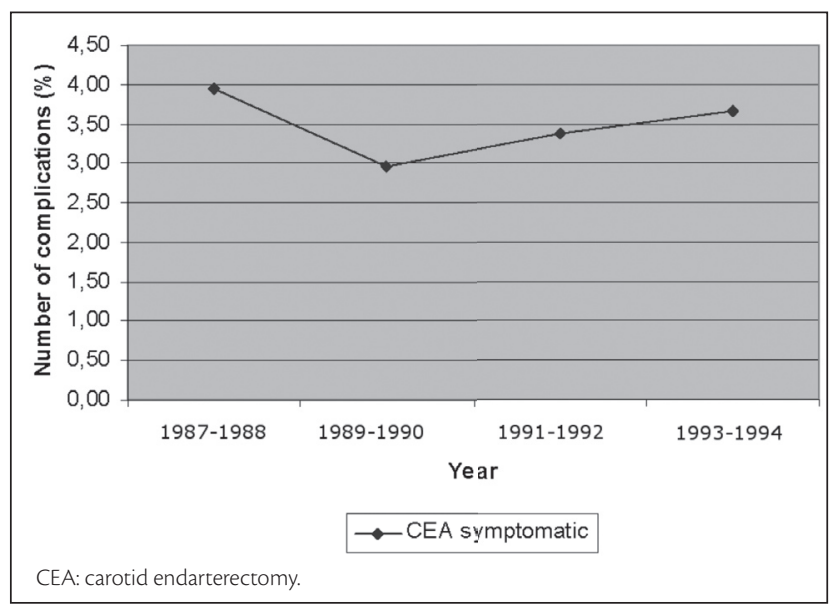

Figure 2 - Number of complications in symptomatic patients from 1987 to 1994
The stroke/death rate of $9.26 \%$ in our first 125 consecutive patients is comparable to the outcome of the survey by Wholey et al. ${ }^{8}$ They found a stroke/death rate of $8.3 \%$ after CAS. Reasons for this high complication rate are lack of experience, unavailability of embolic protection devices and absence of dedicated carotid devices. The evolution in the number of carotid interventions and the number of complications between 1995 and 2000 are shown in Figures 3 and 4.

In 2000, the poor outcome of this early period changed with the introduction of cerebral protection devices. Since then, CAS, in our department, was no longer preserved for patients with increased risk of complications during CEA. The introduction of cerebral protection devices is not the sole reason for the more favourable stroke/death rates seen recently: we benefited from an early start with CAS, and did no longer have to encounter the steep learning curve as described by Ahmadi et al. ${ }^{9}$ More important was the simultaneous introduction of dedicated endovascular carotid devices for CAS. Compared with

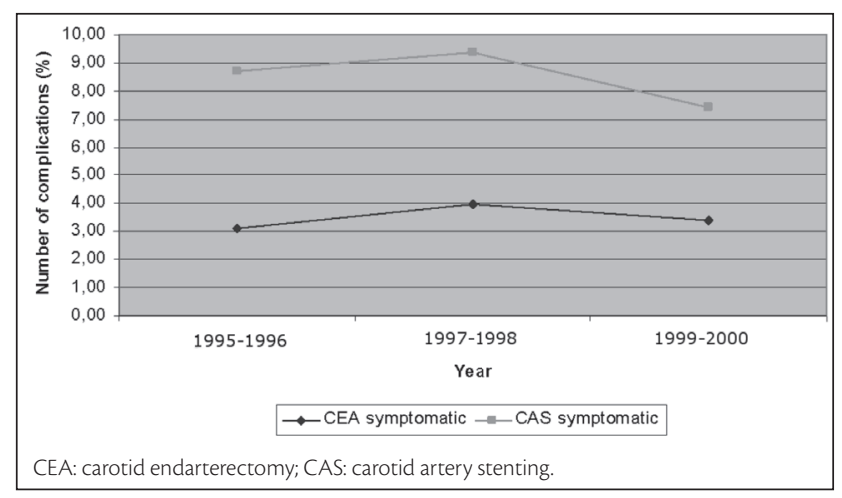

Figure 4 - Number of complications in symptomatic patients from 1995 to 2000

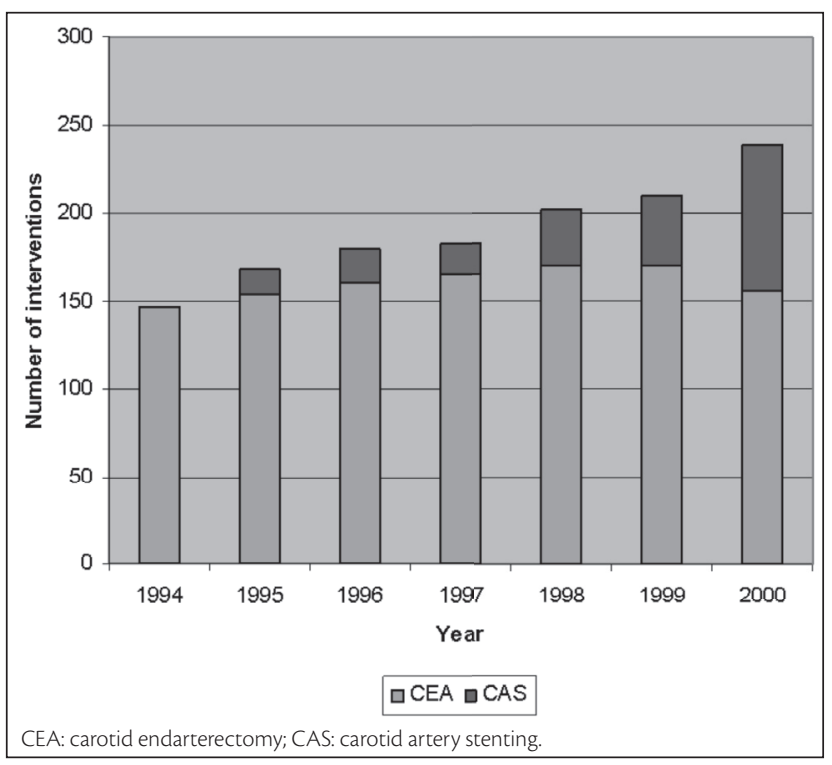

Figure 3 - Number of carotid interventions from 1995 to 2000 
the general peripheral devices used previously, these devices had a significantly lower profile resulting in less complications during the procedure, and therefore resulting in a combined 30 day stroke/death rate for CAS of $2.12 \%$, comparable to ours for CEA of $2.30 \%$, until 2004. Figures 5 and 6 illustrate this phase in our carotid treatment paradigm between 2000 and 2004.

Between 2004 and 2006, the number of patients submitted to CAS increased. CAS became a very attractive procedure: dedicated carotid stents, the use of protection devices, the use of local anaesthesia and no scar tissue on the neck led to a more liberate use of the procedure. In consequence, the complication rates in that period were $3.21 \%$ for symptomatic patients and $1.51 \%$ for asymptomatic ones. Figures 7 and 8 overview the evolution during this period in the number of carotid interventions and the number of complications in symptomatic patients.

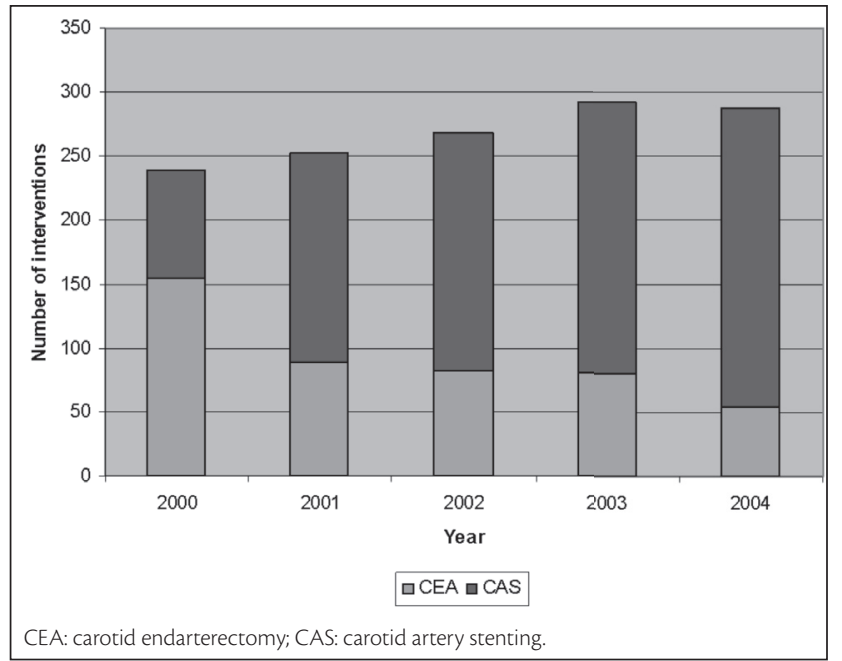

Figure 5 - Number of carotid interventions from 2000 to 2004

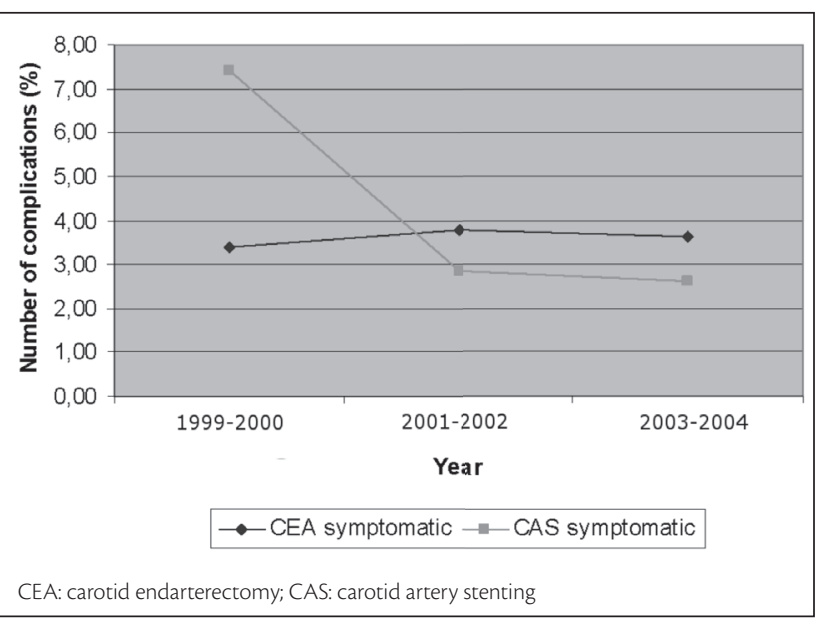

Figure 6 - Number of complications in symptomatic patients from 1999 to 2004
In 2006, after the publications of the EVA $3 S^{10}$ and the SPACE trials ${ }^{11}$, we became more selective in performing CAS mainly in symptomatic patients, as shown in Figure 9. In consequence, the numbers of CEA increased. In parallel,

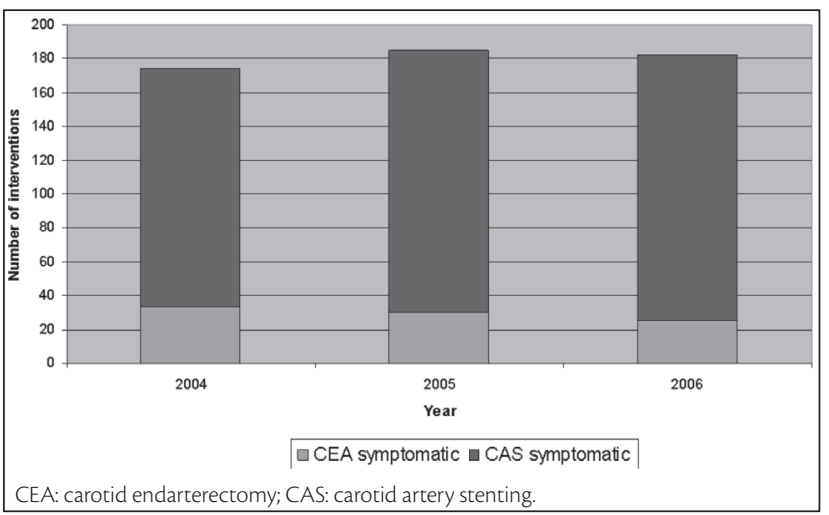

Figure 7 - Number of carotid interventions in symptomatic patients from 2004 to 2006

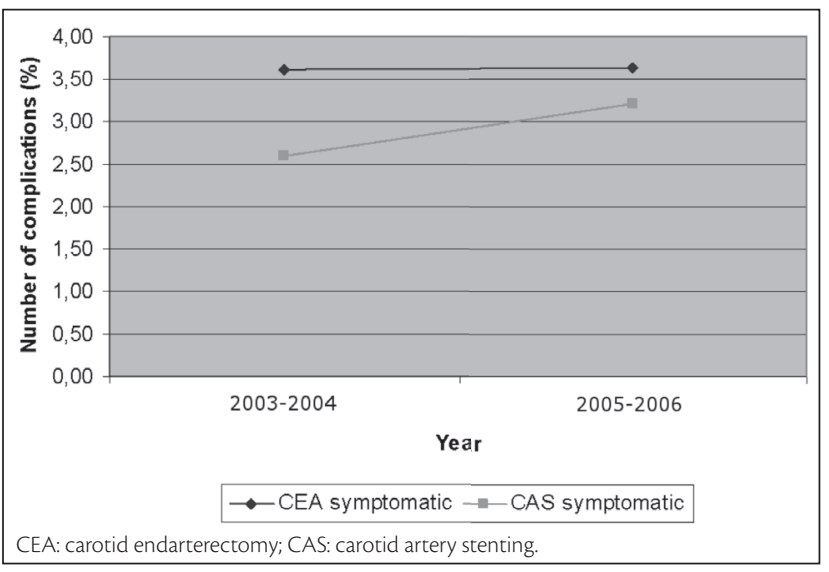

Figure 8 - Number of complications in symptomatic patients between 2003 and 2006

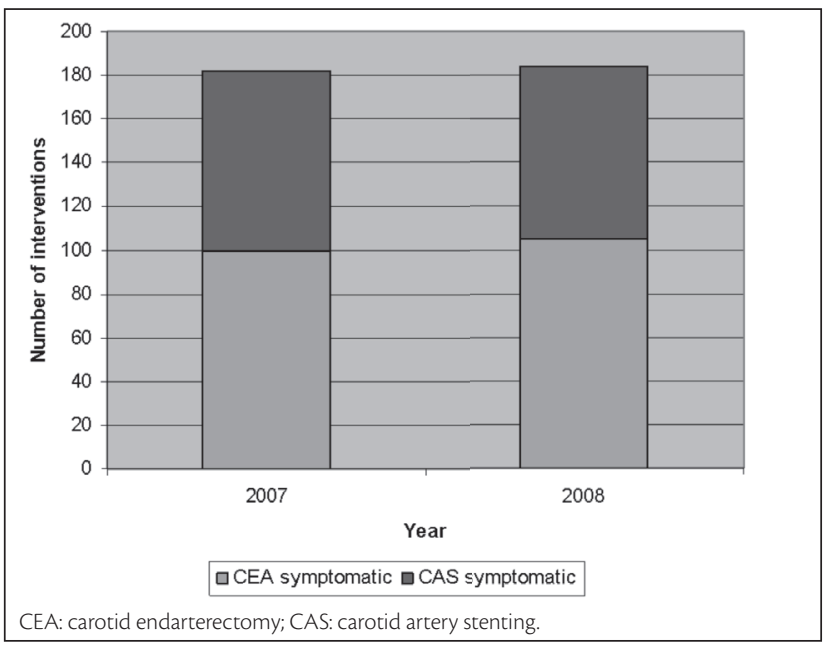

Figure 9 - Number of carotid interventions in symptomatic patients from 2007 to 2008 
the complication rates after CAS for symptomatic patients decreased to $1.24 \%$ and to $0.53 \%$ for asymptomatic patients, which can be seen in Figure 10.

\section{Discussion}

Only vascular surgeons who are able to perform both CEA and CAS perfectly understand that both procedures are complementary and not concurrent. Approximately $80 \%$ of all patients presenting with CAD are eligible for both CAS and CEA. In the remaining 20\%, careful attention must be paid to predisposing factors increasing the risk for complications with one or the other technique. In contrast to some other publications that can be found in the literature ${ }^{12,13}$, we firmly believe that CAS has an important role to play in the treatment of patients with CAD, if patient selection is performed correctly.

Asymptomatic patients presenting with medical comorbidities, such as severe chronic obstructive pulmonary disease, left ventricular ejection fraction lower than $30 \%$, unstable angina pectoris or recent myocardial infarction, are considered high risk. They are ruled out for CEA because of the increased risk of perioperative complications. The decision whether to opt for medical treatment or CAS depends on the patient's life expectancy. High-risk patients are more likely to decease from their concomitant disease rather than from stroke, meaning that the primary pathology has to be treated first. Treating the carotid stenosis in this circumstance would not benefit the patient in terms of life expectancy. Therefore, the only justified treatment for patients with untreated comorbidity is medical care. Nevertheless, in our service, medical treatment is the only alternative when treatment of underlying disease does not imply an improvement in patient's life expectancy.

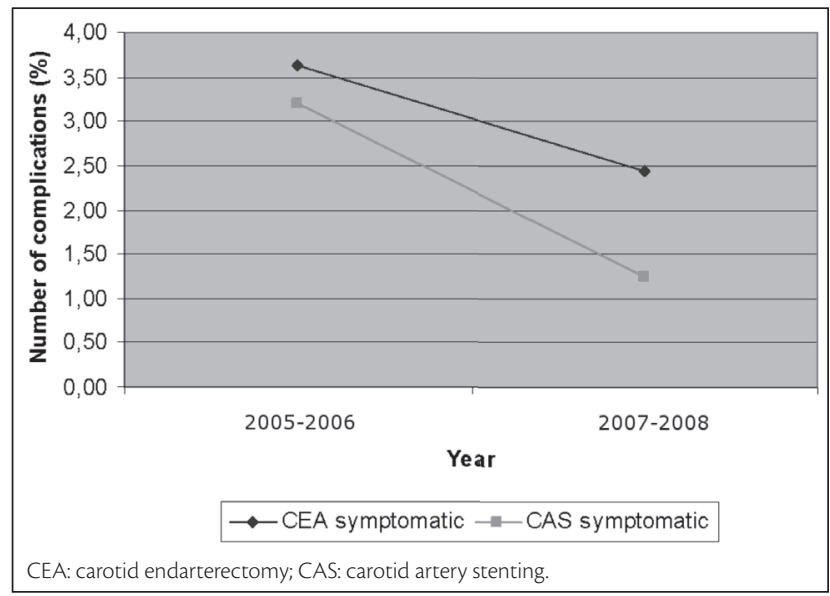

Figure $\mathbf{1 0}$ - Number of complications in symptomatic patients from 2005 to 2008
In our institution, low-risk asymptomatic patients with a stenosis of over $80 \%$ are never medically treated. Patients with anatomical limitations for CEA (hostile neck, restenosis after carotid endarterectomy, radiotherapy, distal bifurcation, Takayasu's disease and fibromuscular dysplasia) are assigned to CAS treatment. Then, the remaining patients with an anatomy that excludes CAS (severely tortuous, calcified and atherosclerotic aortic arches, severe tortuosities or kinking of the bifurcation, sub-total occlusions or string lesions and evidence of thrombus) automatically undergo CEA treatment. If the patient fits both CAS and CEA, we let him/her choose the treatment because the complication rates between these modalities do not differ significantly in our institution.

Since 2000, we can observe that the number of CAS procedures for asymptomatic patients is stable.

In symptomatic patients, we observed a change in our practice in the last two years.

Between 2006 and 2008, we performed 548 carotid revascularizations. In the year 2006, CAS represented approximately $86 \%$ of all cases. In 2007 and 2008, this rate decreased to approximately $43 \%$. In consequence, the number of patients submitted to CEA was higher.

In the Department of Vascular Surgery of the A.Z. SintBlasius, Dendermonde, Belgium, CAS is only indicated as the treatment of choice in symptomatic patients, when important comorbidities and a high-risk lesion have been recognized. An overview of the number of complications from 1995 to 2008 can be seen in Figure 11.

The age of the patient plays an important role and it is associated with neurological complications. In the carotid revascularization, Endarterectomy versus Stent Trial (CREST) and Stent-Supported Percutaneous Angioplasty of the Carotid Artery versus Endarterectomy (SPACE) trials report that increasing age has been directly related to

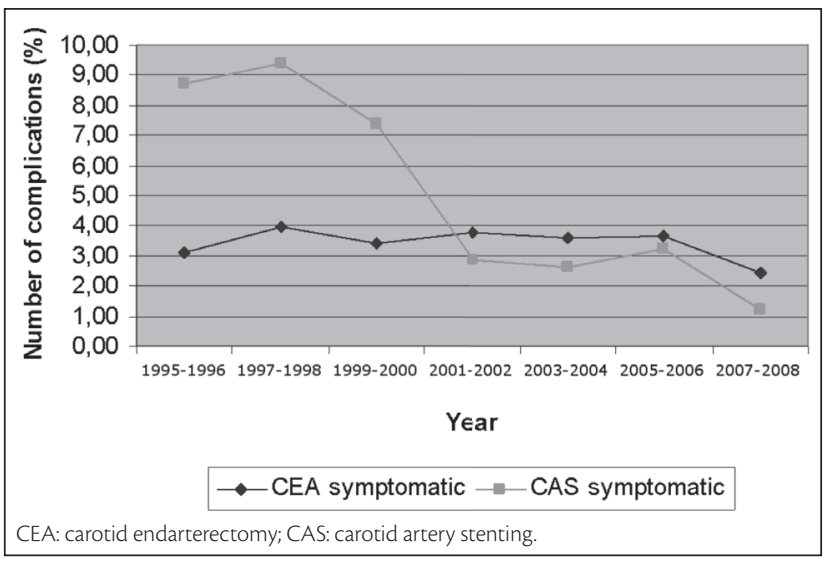

Figure 11 - Number of complications from 1995 to 2008 
a higher number of neurological complications at 30 days after $\mathrm{CAS}^{11,14}$.

Differently of the CEA, in which the access to the vessel is direct, when CAS is planned, the route to the lesion has to be analyzed. Pre-procedural mapping of the access vessels is important to exclude CAS for patients presenting with decreased accessibility due to tortuous iliac and/or diseased or elongated aortic arches. In order to develop a scoring system to facilitate case selection for CAS, an expert consensus (The Delphi Consensus) was published and can be used to categorize expected difficulty of carotid artery stenting and aid case selection ${ }^{15}$.

Early carotid revascularization after acute stroke is advised in order to prevent recurrent events. However, Topakian et al. clearly indicate that CAS is not the preferred strategy for recent stroke because of the higher rates of 30 days stroke and deaths when CAS was performed during the first 2 weeks following an acute stroke ${ }^{16}$.

Heavy circumferencial calcification is an important predictor of CAS-related complications. As the presence of highly calcified concentric plaques causes difficulties in the tracking and positioning of the stents and, as to date, carotid stents that offer enough radial force to adequately achieve optimal stent expansion are not available, CEA is probably the best option for this category of patients ${ }^{17}$.

Patients with vulnerable plaque are at increase risk of complications after CAS. The ICAROS trial concluded that carotid plaques with grey scale median $(\mathrm{GSM})<25$ are defined as echogenic and that in these patients the risk of stroke in CAS is significantly increased $(p=0.005)^{18}$. So in these patients CEA should be performed.

Approximately $2 / 3$ of all events occur after the procedure, and are probably caused by late emboli through the struts of the stent ${ }^{19}$. After removal of the embolic protection device, the only protection against brain embolization remains the selected carotid stent. Therefore, the stent scaffolding capacities are of major importance to obtain a result of CAS free from stroke. We found that symptomatic patients and patients with echolucent lesions had an approximate four times lower risk of 30-day transient ischemic attack, stroke and death after implantation of a closed cell carotid stent compared with open cell stents ${ }^{20}$. If the selection of stent with such high scaffolding capacities potentially compromises the maintenance of initial anatomy of the vessel (e.g. potential distal kink or significant mismatch in proximal and distal diameter), the authors can only recommend to perform CEA in these cases.

Therefore, symptomatic patients have to fit all these criteria to be submitted to CAS. Otherwise, CEA will be the procedure of choice. If the patient has important comorbidities and is not fit to receive CAS as a treatment, we tend to offer medical treatment as an option. This method selection is reflected in an increased number of CEA in the symptomatic population and also in a decreased number of complication rates.

\section{Conclusion}

Vascular surgeons who can offer both CEA and CAS in the same service are best placed to treat the CAD population. The right selection of patients is crucial to have good results in both CAS and CEA.

In asymptomatic patients who fit the selection criteria, CAS is a good choice of treatment.

In spite of this era of technological breakthroughs, we are performing more CEA procedures in symptomatic patients again, and we have observed less complications with this approach.

\section{References}

1. Carrea R, Molins M, Murphy G. Surgical treatment of spontaneous thrombosis of the internal carotid artery in the neck. Carotidcarotideal anastomosis. Report of a case. Acta Neurol Latinoamer. 1955; 1:71-8.

2. Struly KJ, Hurwitt ES, Blankenberg HW. Thromboendarterectomy for thrombosis of the internal carotid artery in the neck. ) Neurosurg. 1953;10:474-82.

3. DeBakey ME. Carotid endarterectomy revisited. J Endovasc Surg. 1996;3:4.

4. Yadav JS, Wholey MH, Kuntz RE, Fayad P, Katzen BT, Mishkel G), Bajwa TK, Whitlow P, Strickman NE, Jaff MR, Popma J), Snead DB, Cutlip DE, Firth BG, Ouriel K; Stenting and Angioplasty with Protection in Patients at High Risk for Endarterectomy Investigators. Protected carotid-artery stenting versus endarterectomy in highrisk patients. N Engl J Med. 2004;351:1493-501.

5. CaRESS Steering Committee. Carotid Revascularization Using Endarterectomy or Stenting Systems (CaRESS) phase I clinical trial: 1-year results. J Vasc Surg. 2005;42:213-9.

6. Bosiers M, Peeters P, Deloose K, et al. Does carotid artery stenting work on the long run: 5-year results in high-volume centers (ELOCAS Registry). J Cardiovasc Surg (Torino). 2005;46:241-7.

7. Bergeron P, Roux M, Khanoyan P, Douillez V, Bras J, Gay J. Longterm results of carotid stenting are competitive with surgery. J Vasc Surg. 2005;41:213-21.

8. Wholey $\mathrm{MH}$, Wholey $\mathrm{M}$, Bergeron $\mathrm{K}$, et al. Current global status of carotid artery stent placement. Cathet Cardiovasc Diagn. 1998;44:1-6.

9. Ahmadi R, Willford A, Lang W, et al. Carotid artery stenting: effect of learning curve and intermediate-term morphological outcome. J Endovasc Ther. 2001;8:539-46.

10. Mas JL, Chatellier G, Beyssen B, Branchereau A, Moulin T, Becquemin JP, Larrue V, Lièvre M, Leys D, Bonneville JF, Watelet J, Pruvo JP, Albucher JF, Viguier A, Piquet P, Garnier P, Viader F, TouzéE, 
Giroud M, Hosseini H, Pillet JC, Favrole P, Neau JP, Ducroca X; EVA$3 S$ Investigators. Endarterectomy versus stenting in patients with symptomatic severe carotid stenosis. N Engl J Med. 2006;355:166071.

11. SPACE Collaborative Group, Ringleb PA, Allenberg J, Brückmann H, Eckstein $\mathrm{HH}$, Fraedrich $\mathrm{G}$, et al. 30 day results from the SPACE trial of stent-protected angioplasty versus carotid endarterectomy in symptomatic patients: a randomised non-inferiority trial. Lancet. 2006;368:1239-47.

12. Bonamigo TP, Lucas ML, Análise crítica das indicações e resultados do tratamento cirúrgico da doença carotídea [revisão]. J Vasc Bras. 2007;6:366-77.

13. Tinoco $E C A$, Silva $L F$, Luquini $B B$, Campanha $R$, Nascimento $M$, Horta L. Estudo prospectivo comparativo entre a endarterectomia e a angioplastia com stent e proteção cerebral no tratamento das lesões ateroscleróticas carotídeas: resultados em 30 dias. J Vasc Bras. 2006;5:257-62.

14. Hobson RW 2nd, Howard VJ, Roubin GS, Brott TG, Ferguson RD, Popma JJ, Graham DL, Howard G; CREST Investigators. Carotid artery stenting is associated with increased complications in octogenarians: 30 -day stroke and death rates in the CREST lead-in phase. J Vasc Surg. 2004;40:1106-11.

15. Macdonald S, Lee R, Williams R, Stansby G; Delphi Carotid Stenting Consensus Panel. Towards safer carotid artery stenting: a scoring system for anatomic suitability. Stroke. 2009;40:1698703.

16. Topakian R, Strasak A, Sonnberger M, et al. Timing of stenting of symptomatic carotid stenosis is predictive of 30-day outcome. Eur J Neurol. 2007;14:672-8.
17. Bosiers $M$, Deloose K, Verbist J, Peeters P. What practical factors guide the choice of stent and protection device during carotid angioplasty? Eur I Vasc Endovasc Surg. 2008;35:637-43.

18. Biasi G, Froio A, Diethrich E, et al. Carotid plaque echolucency increases the risk of stroke in carotid stenting: the Imaging in Carotid Angioplasty and Risk of Stroke (ICAROS) study. Circulation. 2004; 10:756-62.

19. Cremonesi A, Setacci C, Manetti R, et al. Carotid angioplasty and stenting: lesion related treatment strategies. Eurolntervention. 2005;1:289-95.

20. Hart JP, Peeters P, Verbist J, Deloose K, Bosiers M. Do device characteristics impact outcome in carotid artery stenting? J Vasc Surg. 2006;44:725-30.

Correspondence: Marc Bosiers

Department of Vascular Surgery - A.Z. Sint-Blasius Kroonveldlaan 50 B-9200 Dendermonde, Belgium E-mail: marc.bosiers@telenet.be

Author's contribution: Conception and design: $M B$ Analysis and interpretation: $M B, K D$ Data collection: GHDK Writing the article: $M B, G H D K, K D$ Critical revision of the article: $M B, K D, T P N$ Final approval of the article*: MB, GHDK, KD, TPN Statistical analysis: MB, GHDK, KD, TPN Overall responsibility: $M B, G H D K, K D, T P N$ Obtained funding: N/A *All authors have read and approved the final version of the article submitted to J Vasc Bras. 